\title{
INFLUÊNCIA DE ALGUNS MÉTODOS DE PROCESSAMENTO NA QUALIDADE DA MAÇÃ EM PEDAÇOS: III - Variedade Rome Beauty*
}

\author{
JoÃo NUNES NOGUEIRA **
}

\section{RESUMO}

Este trabalho teve como objetivo o estudo da influência de armazenamento prévio, de tratamentos para evitar o escurecimento enzímico (branqueamento, $\mathrm{SO}_{2}$ e ácido ascórbico) e de métodos de processamento (appertização, congelação e liofilização) na qualidade da maçã em pedaços da variedade Rome Beauty. Após seu recebimento na planta piloto, metade das frutas foi imediatamente processada, permanecendo o restante armazenado por seis semanas a $4,4^{\circ} \mathrm{C}$ para ser posteriormente processado.

O melhor tratamento para a variedade em estudo, foi a combinação branqueamento-congelação para todos os atributos de qualidade, exceto para cor com seis semanas de armazenamento prévio, em que a combinação $\mathrm{SO}_{2}$-liofilização foi superior. De um modo geral, a congelação foi o método de processamento mais adequado. Para a congelação, o branqueamento e o $\mathrm{SO}_{2}$ foram considerados os melhores tratamentos para evitar o escurecimento enzímico. $\mathrm{O}$ armazenamento prévio teve alguma influência na qualidade da maçã em pedaços, de modo que, as amostras correspondentes à parte não armazenada foram superiores para quase todos os atributos de qualidade.

\section{INTRODUÇÃO}

O processamento de maçã é, sem dúvida, uma indústria de grande importância na atualidade. Nos EUA, cerca de metade da produção total de maçã é processada, principalmente na forma da fruta em pedaços.

Para o processamento é necessário adaptar e selecionar variedades, utilizar (quando necessário) armazenamento prévio adequado, bem como técnicas de processamento satisfatórias afim de que se possa

* Trabalho realizado na Universidade Estadual de Ohio, USA, com o auxílio financeiro do Convênio USAID/OSU/ESALQ - Entregue para publicação em 16-12-1976

* Professor Assistente Doutor, Depto. de Tecnologia Rural, ESALQ - USP 
oferecer ao mercado consumidor um produto de qualidade tal que satisfaça a sua exigência, que se torna cada vez maior com o passar dos anos.

A seleção de variedades adequadas para o processamento é um importante passo no sentido de se obter um produto de alta qualidade. Uma determinada variedade pode possuir qualidades muito boas com relação à produção, resistência à doenças e época de maturação adequada, porém, pode não ser recomendada devida à sua baixa qualidade para processamento (GALLANDER, 1965). Segundo LEWIS \& MARTIN (1965), MARTIN et al. (1967) e WILLS (1968), o armazenamento que precede o processamento também deve ser considerado, porque durante este período ocorrem mudanças físicas e químicas que podem melhorar ou deteriorar a qualidade das frutas.

Outro fator que pode afetar a qualidade da maçã em pedaços é o escurecimento que normalmente ocorre no produto durante o processamento. De acordo com BOUCHILLOUX (1962), BRAVERMAN (1963) e CORSE (1964) este escurecimento é resultante de oxidações enzímicas e pode ser evitado pelo emprego de métodos de controle adequados. Embora vários métodos tenham sido recomendados, CALDWELL et al. (1955), GULLETT (1957-1958), PONTING (1960) e HOPE (1961) relataram que ainda não há pleno acordo entre os pesquisadores, quanto ao que seria mais satisfatório para o controle do escurecimento enzímico da maçã.

Segundo DAVIS (1961), LUYET (1961), SALUNKHE et al. (1965) e STERLING (1968) a qualidade do produto processado é também afetada pelo método de processamento utilizado. Uma determinada variedade pode ser apropriada para a congelação, porém, pode não sê-lo para a appertização ou desidratação. Deste modo, a seleção do método de processamento adequado para uma determinada variedade, é de grande importância.

Com o conhecimento desses problemas, o autor se propôs a estudar a variedade Rome Beauty, visando os seguintes objetivos:

a) Verificar se a variedade em estudo é apropriada para processamento.

b) Estudar a influência de alguns métodos de processamento na qualidade da maçã em pedaços.

c) Estudar a eficiência de alguns tratamentos no controle do ascurecimento enzímico da maça em pedaços, após o processamento.

d) Determinar o efeito do armazenamento prévio na qualidade da maçã em pedaços, depois de processada. 


\section{MATERIAL E MÉTODOS}

A variedade em estudo, Rome Beauty, foi obtida nos pomares da Estação Experimental da Universidade Estadual de Ohio, em Wooster, Ohio. As frutas foram colhidas num estágio de amadurecimento considerado ótimo para consumo "in natura". Após a colheita, as maçãs foram imediatamente transportadas para a planta piloto do Departamento de Horticultura da Universidade Estadual de Ohio. Após seu recebimento, metade das frutas foi imediatamente processada. A parte restante foi colocada em câmara fria a $4,4^{\circ} \mathrm{C}$ onde permaneceu armazenada por seis semanas, sendo em seguida também processada.

Para o processamento foram utilizados seis tratamentos para cada lote de frutas em cada tempo de armazenamento prévio. Resumindo, os tratamentos utilizados, identificados com letras de A a F, foram os seguintes: A (branqueamento-appertização), B (ácido ascórbico-congelação), $\mathrm{C}\left(\mathrm{SO}_{2}\right.$-congelação), D (branqueamento-congelação), E ( $\mathrm{SO}_{2}-$ -liofilização) e F (branqueamento-liofilização).

O preparo das maçãs foi feito por meio de uma máquina especial (Boutell MFG. Co.) que procedeu o descascamento retirando ao mesmo tempo a parte central dura que contém as sementes. As frutas foram então examinadas quanto à possíveis defeitos e em seguida colocados em uma outra máquina (F.B. Pease Co.) que as cortou em doze pedaços. O material assim preparado, foi colocado em recipientes contendo solução de cloreto de sódio a $2 \%$ onde permaneceu imerso até que fosse aplicado o tratamento definitivo para evitar o escurecimento enzímico (branqueamento, $\mathrm{SO}_{2}$ ou ácido ascórbico).

\section{Branqueamento}

O branqueamento foi feito em câmara apropriada (contendo vapor a $100^{\circ} \mathrm{C}$ ) onde os pedaços de maçã eram colocados durante um minuto e quarenta e cinco segundos. O tempo mais adequado de branqueamento foi determinado utilizando-se para verificação da eficiência do tratamento, o teste do catecol (USDA, 1945). Após o branqueamento os pedaços de maçã foram imediatamente resfriados por um dispositivo contendo uma série de jatos de água.

\section{Tratamento com $\mathrm{SO}_{2}$}

Neste tratamento, o bisulfito de sódio foi utilizado como fonte de $\mathrm{SO}_{2}$. A solução foi preparada de modo a conter $2.500 \mathrm{ppm} \mathrm{de} \mathrm{SO}_{2}$, sendo a sua temperatura de cerca de $21^{\circ} \mathrm{C}$. Os pedaços de maçã foram imersos por um minuto nesta solução, sendo em seguida colocados em bandejas onde permaneceram em repouso, ao ar livre, por oito horas e trinta 
minutos. Este tempo utilizado, suficiente para a completa inativação das enzimas, foi também determinado pelo teste do catecol.

\section{Tratamento com Ácido Ascórbico}

Os pedaços de maçã foram tratados com ácido ascórbico na proporção de $350 \mathrm{mg}$ por quilo de fruta, adicionados ao xarope de sacarose a $40^{\circ}$ Brix em que foram acondicionados.

\section{Acondicionamento}

Após o tratamento, os pedaços de maçã foram acondicionados, apenas para fins de armazenamento, em latas n. $303(8,09 \times 11,11 \mathrm{~cm})$, com revestimento interno de verniz. As frutas liofilizadas também foram acondicionadas no mesmo tipo de latas.

\section{Appertização}

Foram colocadas em cada lata $284 \mathrm{~g}$ de fruta (branqueada) completando-se o volume com xarope de sacarose a $40^{\circ}$ Brix. Em seguida foi feita a exaustão a vapor, em túnel apropriado, durante dois minutos e quarenta e cinco segundos sendo as latas imediatamente fechadas por uma recravadeira automática (American Can Co. 006) ajustada para dar uma pressão de vapor de 15 psi. O material assim preparado foi esterilizado em autoclave por 10 minutos a $100^{\circ} \mathrm{C}$, sendo as latas em seguida resfriadas em água corrente e armazenadas à temperatura ambiente por dois meses.

\section{Congelação}

A parte das frutas destinada à congelação, foi devidamente acondicionada com xarope de sacarose a $40^{\circ} \mathrm{Brix}$, em latas que foram fechadas hermeticamente e colocadas em um congelador a $-29^{\circ} \mathrm{C}$. Em cada lata foram colocadas $227 \mathrm{~g}$ de pedaços de maçã quimicamente tratados $\left(\mathrm{SO}_{2}\right.$ ou ácido ascórbico). No caso dos pedaços branqueados, foram colocados em cada lata $284 \mathrm{~g}$ de fruta. Com o branqueamento os pedaços de maçã tornam-se mais flexíveis o que permite a colocação de uma quantidade maior de material em cada lata. Após o congelamento o material foi armazenado em câmaras apropriadas, a $-23^{\circ} \mathrm{C}$, por dcis meses.

\section{Liofilização}

Os pedaços de maçã a serem liofilizados (tratados com $\mathrm{SO}_{2}$ e branqueados) foram colocados diretamente nas bandejas do liofilizador 
e congelados a $-29^{\circ} \mathrm{C}$. Atingida esta temperatura, as bandejas foram retiradas do congelador e levadas para o liofilizador (Stokes - modelo piloto) para o início da operação de desidratação propriamente dita. A câmara de liofilização foi então hermeticamente fechada e o sistema de vácuo ligado para congelar a superfície do produto que por acaso tivesse sido descongelada durante sua transferência para o aparelho. Quando a temperatura do produto atingiu $-32^{\circ} \mathrm{C}$, a temperatura das prateleiras foi elevada para $24^{\circ} \mathrm{C}$ e duas horas mais tarde foi mantida entre 46 e $49^{\circ} \mathrm{C}$ até o final da desidratação. O vácuo na câmara de liofilização foi mantido entre 0,2 e 0,3 micron de $\mathrm{Hg}$ durante toda a operação. Cada ciclo de liofilização teve a duração de 12 a 16 horas, dependendo do tamanho e da espessura dos pedaços de maçã.

Quando a temperatura do produto atingiu a temperatura das prateleiras, ou seja, 46 a $49^{\circ} \mathrm{C}$, considerou-se por terminada a operação de desidratação. O liofilizador foi então desligado e o vácuo quebrado com ar. Os pedaços de maçã desidratados foram imediatamente acondicionados em latas que foram, em seguida, hermeticamente fechadas e armazenadas à temperatura ambiente por dois meses.

\section{Avaliação Organolética}

A qualidade dos pedaços de maça processados pelos diferentes métodos, após dois meses de armazenamento, foi avaliada na forma de torta de maçã. Este método de avaliação é bastante válido uma vez que o material é praticamente reprocessado (DALRYMPLE \& FEUSTEL, 1965 e GOULD, 1968).

Para a confecção das tortas foi utilizada uma receita padrão segundo McDERMOTT et al. (1967), tomando-se o cuidado de não empregar nenhum aditivo que pudesse prejudicar a avaliação da qualidade dos pedaços de maçã. As tortas foram assadas em forno elétrico automático, rotativo, por 15 minutos a $204^{\circ} \mathrm{C}$ e por mais 35 minutos a $177^{\circ} \mathrm{C}$.

A qualidade dos pedaços de maçã das tortas, foi avaliada em termos de cor, sabor e textura por uma equipe de dez julgadores, selecionada e treinada para este tipo de avaliação (DAWSON, 1964). Cada amostra, correspondente a dado tratamento foi servida ao julgador duas vezes, porém em sessões consecutivas, para assegurar uma melhor avaliação do produto. A amostra consistiu em um pedaço correspondente a 1/12 da torta, cortado em forma de cunha. As amostras previamente codificadas, foram servidas em bandejas de alumínio, e cada julgador avaliou os produtos dando-lhes nota de 1 a 10 para cor, sabor e textura, sendo adotado o seguinte critério: 1 - péssimo; 2 , 3 - ruim; 4, 5, 6 - regular; $7,8,9$ - bom e 10 - ótimo. A avaliação foi feita em cabines individuais, especialmente desenhadas para finalidades dessa natureza. 


\section{Métodos Estatisticos}

Para a análise estatística os resultados obtidos foram agrupados segundo recomendações de GOULD (1968), sendo tiradas as médias aritméticas das duas notas dadas por julgador, a cada tratamento. A qualidade geral de cada tratamento foi obtida tomando-se a média das notas dadas, por julgador, para cor, sabor e textura.

Os resultados foram estatisticamente analisados utilizando-se a análise da variância e o teste F (GOMES, 1970). Não foi feito cálculo do valor de $\mathbf{F}$ para julgadores uma vez que a diferenciação entre os mesmos, no experimento, não é de importância. A análise dos resultados foi feita considerando o grupo de julgadores como um todo (GOULD, 1968).

A comparação das médias dos tratamentos, duas a duas, foi feita utilizando-se o DMS (diferença mínima significativa), segundo KRAMER \& TWIGG (1966), que foi calculado somente nos casos em que os valores de $\mathrm{F}$ foram significativos ao nível de 5 ou $1 \%$ de probabilidade.

\section{RESULTADOS E DISCUSSÃO}

Os resultados aqui apresentados para cor, sabor, textura e qualidade geral (QUADROS 1 e 2) correspondem às médias das notas dadas pelos dez julgadores.

Pela observação dos QUADROS 1 e 2, pode-se constatar que foi evidente a influência dos métodos de processamento na qualidade da maçã em pedaços, em cada tempo de armazenamento prévio.

Fazendo uma comparação geral entre os tratamentos com zero e seis semanas de armazenamento prévio, conclui-se que o tratamento $D$ foi considerado o melhor para todos os atributos de qualidade, exceto para cor, em que o tratamento $\mathbf{C}$ (com zero e seis semanas) e o tratamento $\mathrm{E}$ (com seis semanas) foram superiores. De um modo geral, os tratamentos A e E com zero semanas de armazenamento e os tratamentos B e F com seis semanas, foram os piores tratamentos para todos os atributos de qualidade.

Para a congelação (tratamentos B, C e D) com zero semanas de armazenamento, praticamente não houve diferença entre os métodos utilizados para evitar o escurecimento enzímico (QUADRO 1). Com seis semanas de armazenamento prévio (QUADRO 2) as amostras tratadas com $\mathrm{SO}_{2}$ e as branqueadas, foram consideradas superiores iquelas tratadas com ácido ascórbico. 
QUADRO 1 - Influência dos métodos de processamento na qualidade da maçã em pedaços com zero semanas de armazenamento

\begin{tabular}{c|c|c|c|c}
\hline \multirow{2}{*}{ Tratamentos } & \multicolumn{4}{|c}{ Média dos tratamentos (10 julgadores) } \\
\cline { 2 - 5 } & Cor & Sabor & Textura & Qual. Geral \\
\hline \hline A - Br.-appert. & 5,45 & 7,40 & 5,80 & 6,21 \\
B - A.a.-cong. & 7,45 & 7,40 & 7,15 & 7,33 \\
C - SO -cong. & 8,10 & 6,75 & 7,05 & 7,30 \\
D - Br.-cong. & 7,85 & 7,90 & 7,65 & 7,80 \\
E - $\mathrm{SO}_{2}$-liof. & 7,10 & 6,30 & 5,55 & 6,31 \\
F - Br.-liof. & 6,85 & 6,45 & 5,75 & 6,35 \\
\hline DMS & $0,74^{* *}$ & $0,87^{*}$ & $0,80^{* *}$ & $0,56^{* *}$ \\
\hline
\end{tabular}

QUADRO 2 - Influência dos métodos de processamento na qualidade da maçã em pedaços com seis semanas de armazenamento

\begin{tabular}{|c|c|c|c|c|}
\hline \multirow{2}{*}{ Tratamentos } & \multicolumn{4}{|c|}{ Média dos tratamentos (10 julgadores) } \\
\hline & Cor & Sabor & Textura & Qual. Geral \\
\hline A - Br.-appert. & 5,30 & 6,95 & 6,20 & 6,15 \\
\hline B - A.a.-cong. & 5,60 & 6,05 & 5,65 & 5,76 \\
\hline $\mathrm{C}-\mathrm{SO}_{2}$-cong. & 7,05 & 6,70 & 6,80 & 6,85 \\
\hline $\mathrm{D}-\mathrm{Br} \cdot{ }^{2}$-cong. & 6,70 & 7,25 & 6,95 & 6,96 \\
\hline $\mathrm{E}-\mathrm{SO}_{2}$-liof. & 7,30 & 5,75 & 5,80 & 6,28 \\
\hline $\mathrm{F}-$ Br.-liof. & 5,85 & 5,75 & 5,80 & 5,80 \\
\hline DMS & $0,90^{* *}$ & $0,84^{*}$ & $0,74 * *$ & $0,61 * *$ \\
\hline
\end{tabular}

(*) Significativo ao nível de $5 \%$ de probabilidade.

(**) Significativo ao nível de $1 \%$ de probabilidade. 
Para a liofilização (tratamentos $\mathrm{E}$ e $\mathrm{F}$ ) não foi constatada diferença significativa entre as amostras tratadas com $\mathrm{SO}_{2}$ e as submetidas ao branqueamento, exceto para cor com seis semanas de armazenamento prévio (QUADRO 2), em que o $\mathrm{SO}_{2}$ foi superior.

Pelas Figuras 1, 2, 3 e 4 pode-se ter uma visão geral dos resultados. Assim, quanto à aceitahilidade do produto, levando-se em conta os dois períodos de armazenamento prévio, os tratamentos podem ser classificados na seguinte ordem (decrescente):

a) Cor: C, D, E, B, F e A

b) Sabor: D, A, B, C, F e E

c) Textura: D, C, B, A, F e E

d) Qualidade geral: D, C, B, E, A e F

O armazenamento prévio a que foram submetidas as maçãs, teve alguma influência na aceitação dos diversos tratamentos (Figuras 1, 2,3 e 4). De um modo geral, as amostras correspondentes à parte não armazenada foram julgadas superiores para todos os atributos de qualidade, exceto para os tratamentos E (Figura 1), A, E e F (Figura 3).

O tratamento A foi considerado, quanto à cor, o pior dos tratamenos. Esta observação também foi relatada por DAVIS (1961), que considerou os pedaços de maçã conservados por appertização mais escuros do que aqueles submetidos à congelação. Este escurecimento deve resultar de reaçōes químicas não enzímicas que ocorrem durante o armazenamento do produto processado (BRAVERMAN, 1963). Entretanto, quanto ao sabor, o tratamento $\mathrm{A}$ foi julgado como um dos melhores.

O tratamento $\mathrm{C}$, com relação ao sabor, não foi muito prejudicado pelo $\mathrm{SO}_{2}$, como era esperado. Este composto químico geralmente afeta aquele atributo de qualidade, sendo este fato, a principal objeção à sua utilização como inibidor do escurecimento enzímico em maçã destinada a ser conservada por congelação (USDA, 1945, CALDWELL et al. 1955 e PONTING, 1960).

Os tratamentos E e F (ambos submetidos à liofilização) foram considerados os piores quanto ao sabor e à textura, o que indica ser a variedade em estudo não muito apropriada para este etipo de processamento. Por outro lado LUYET (1961), SALUNKHE et al. (1965) e STERLING (1968) relataram que se o congelamento das amostras não for suficientemente rápido, poderá ocorrer o rompimento de suas células pelos cristais de gelo formados, resultando assim um produto pobre em textura depois que o material for reidratado. 


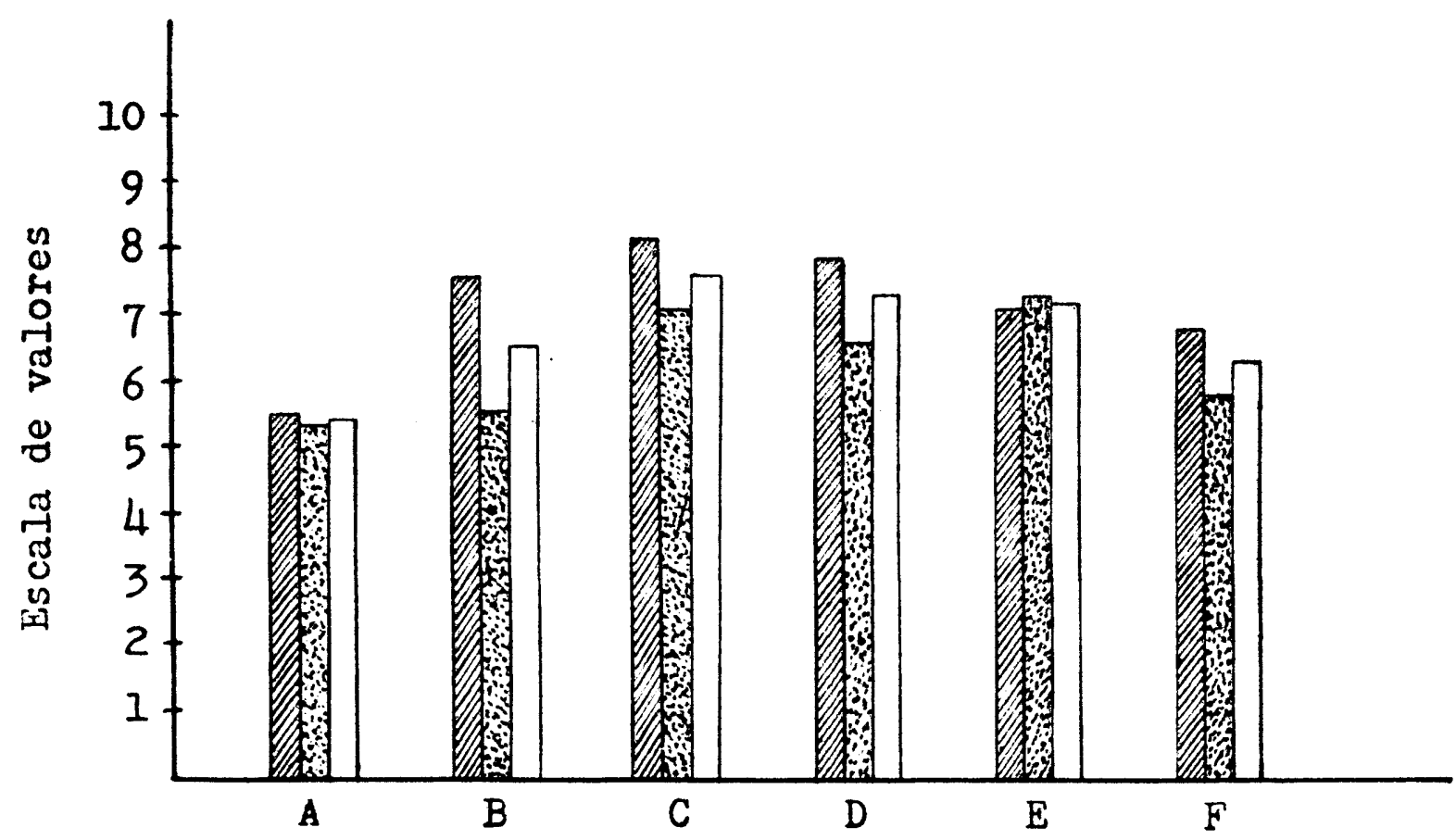

Figura 1. Influência dos métodos de processamento contra tempo de armazenamento prévio na cor da maçã em pedaços.

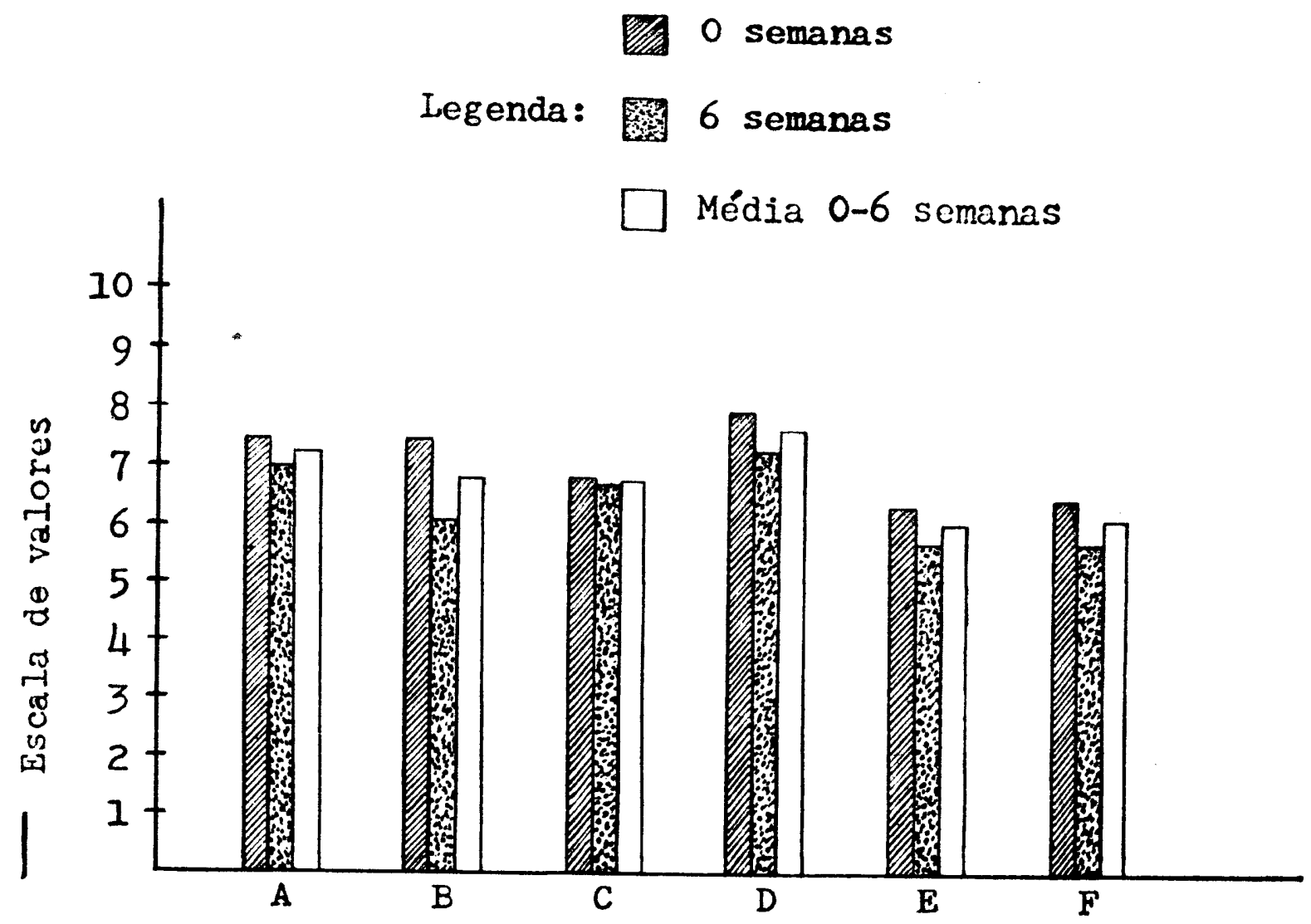

Figura 2. Influência dos métodos de processamento contra tempo de armazenamento prévio na qualidade geral da maçã em pedaços. 


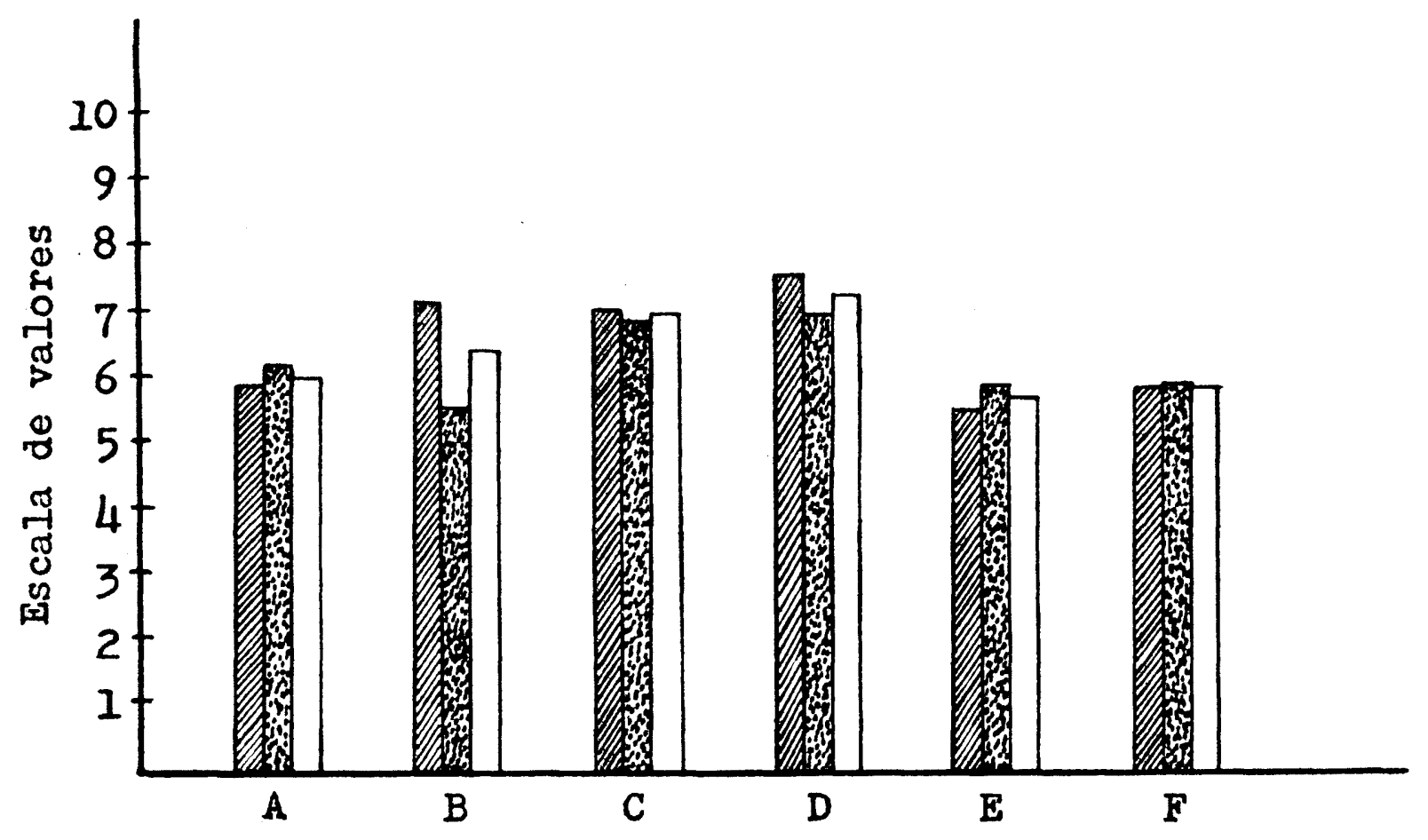

Figura 3. Influência dos métodos de processamento contra tempo de armazenamento prévio na textura da maçã em pedaços.

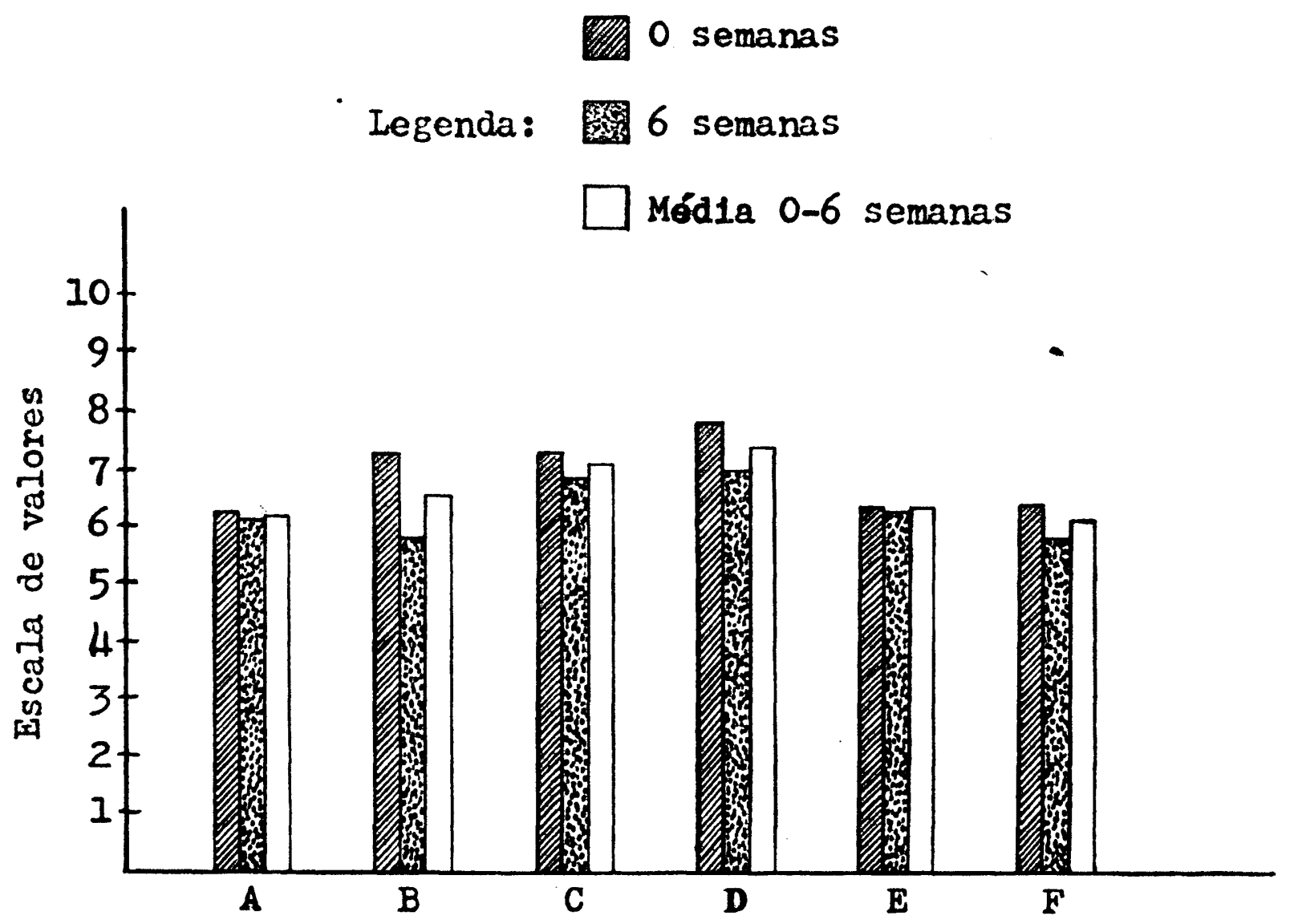

Figura 4. Influência dos métodos de processamento contra tempo de armazenamento prévio no sabor da maçã em pedaços. 


\section{CONCLUSÕES}

Tendo em vista os resultados obtidos, as seguintes conclusões podem ser estabelecidas:

1) O tratamento D (branqueamento-congelação) foi o melhor para todos os atributos de qualidade, exceto para cor, em que o tratamento C ( $\mathrm{SO}_{2}$-congelação) foi superior.

2) A congelação foi, de um modo geral, o método de processamento mais adequado para a variedade em estudo.

3) Quanto à qualidade geral do produto e considerando ambos períodos de armazenamento prévio, a ordem de aceitação dos tratamentos foi a seguinte: D (branqueamento-congelação), C ( $\mathrm{SO}_{2}$-congelação), $\mathrm{B}$ (ácido ascórbico-congelação), $\mathrm{E}$ ( $\mathrm{SO}_{2}$-liofilização), A (branqueamento-appertização) e F (branqueamento-liofilização).

4) Para a congelação, o branqueamento e o $\mathrm{SO}_{2}$ foram os melhores tratamentos para o controle do escurecimento enzímico.

5) Para a liofilização, o tratamento com $\mathrm{SO}_{2}$ foi superior ao branqueamento somente quanto à cor do produto.

6) O armazenamento prévio teve alguma influência na qualidade da maçã em pedaços, de modo que, as amostras correspondentes à parte não armazenada foram superiores para quase todos os atributos de qualidade.

\section{SUMMARY}

INFLUENCE OF SOME PROCESSING METHODS ON THE QUALITY OF APPLE SLICES: III - Variety Rome Beauty

The objective of this paper was to study the influence of storage, browning treatments (blanching, $\mathrm{SO}_{2}$ and ascorbic acid) and processing methods (canning, freezing and freezedryng) on the quality of apple slices of the variety Rome Beauty. Immediately upon arrival at the pilot plant, half of the fruits was processed and the remainder was held in storage for six weeks at $4.4^{\circ} \mathrm{C}$ to be processed later.

The best treatment for the variety under study was the blanching-freezing combination for all attributes of quality, except for color at six week storage, in which the $\mathrm{SO}_{2}$-freezing combination was superior. In general, freezing was the most suitable processing method used. For freezing, blanching and $\mathrm{SO}_{2}$ were considered the best browning treatments. Storage had some influence on the quality of apple slices, so that the zero week storage samples were judged superior for almost all attributes of quality. 


\section{IITERATURA CITADA}

BOUCHILLOUX, S. 1962 - Enzymatic browning reactions. In: RUNECKLES, V.C., ed. - Plant Phenolics and their Industrial Significance. Proceedings of a symposium of The Plant Phenolics Group of North America. p. 1-14.

BRAVERMAN, J.B.S., 1963 - Introduction to the Biochemistry of Foods. Elsevier Publ. Co., New York.

CALDWELL, J.S., C.W. CULPEPPER \& K.D. DEMAREE, 1955 - Quality of frozen apples related to variety and ripeness. Agr. and Food Chem., 3:513-18.

CORSE, J., 1964 - The enzymatic browning of fruits and vegetables. In: RUNECKLES, V.C., ed. - Phenolics in Normal and Diseased fruits and vegetables. Proceedings of a symposium of The Plant Phenolics Group of North America. p. 41-42.

DALRYMPLE, D.G. \& I.C. FEUSTEL, 1965 - Recent developments in the production and marketing of apple sauce and slices. U. S. Department of Agriculture, july. $71 \mathrm{pp}$.

DAVIS, D.R., 1961 - Variety and pretreatment of fruit important for frozen pies. Ohio Farm and Home Res., march-april. p. 27-28.

DAWSON, E.H., 1964 - Sensory testing guide for panel evaluation of foods and beverages. Food Technol., $18: 25-31$.

GALLANDER, J.F., 1965 - Influence of variety and storage on the quality of canned apple slices. Research Summary, $2: 69-72$.

GOMES, F.P., 1970 - Curso de Estatística Experimental, E.S.A. "Luiz de Queiroz". p. $29-41$.

GOULD, W.A., 1968 - Quality Evaluation and Control Manual for Fruits, Vegetables and Related Foods. .Columbus, OSU, Department of Horticulture and Forestry. 126 pp.

GULLETT, E.A., 1957-1958 - Control of browning in frozen apple slices. Report of the Horticultural Expt. Sta. and Products Laboratory, Vineland, Ontario, Canada. p. 143-150.

HOPE, G.H., 1961 - The use of antioxidants in canning apple halves. Food Technol., $15: 548-50$.

KRAMER, A. \& B.A. TWIGG, 1966 - Fundamentals of Quality Control for the Food Industry. The AVI Publ. Co., Connecticut. 541 pp.

LEWIS, T.L. \& D. MARTIN, 1965 - Protein nitrogen content and phosphorylative activity of apple during ripening and senescense. Aust. Journ. Biol. Sci., 18:1093-1101.

LUYET, B.J., 1961 - Effect of freezing rates on the structure of freeze-dried materials and on the mechanism of rehydratation. In: FISHER, F.R., ed. Freeze-drying of Foods. Procedings of a conference at Chicago, Illinois. p. 194-211.

MARTIN, D., T.L. LEWIS \& J. CERNY, 1967 - Nitrogen metabolism during storage in relation to the breakdown of apples. Changes in protein nitrogen level in relation to incidence. Aust. Journ. Agr. Res., 18:271-78.

McDERMOTT, I.E., M.B. TRILling \& F.W. NICOLAS, 1967 - Food for Modern Living. J.B. Lippincott Co., Philadelphia and New York. p. 478-83.

PONTING, J.D., 1960 - The control of enzymatic browning of fruits. In: SCHULTZ, H.W., ed. - Food Enzymes. The AVI Publ. Co., p. 105-124.

SALUNKHE, D.K., L.E. OLSON \& F.S. NURY, 1965 - Chemistry of quality in fruits and fruit products. Farm and Home Sci., september. p. 66-70.

STERLING, C., 1968 - Effect of low temperature on structure and firmness of apple tissue. Journ. Food Sci., 33:577-80.

UNITED STATES DEPARTMENT OF AGRICULTURE, 1945 - Commercial preparation and freezing preservation of sliced apples. Western Regional Res. Lab., Albany, California. 7. pp.

WILLS, R.B.H., 1968 - Influence of water loss on the loss of volatiles by apples. Journ. Sci. Food and Agr., 19:354-56. 